\title{
How to Provide Accurate and Robust Traffic Forecasts Practically?
}

\author{
Yang Zhang \\ Shanghai Municipal Transportation \\ Information Center \\ China
}

\section{Introduction}

With the development of our modern cities, growing traffic problems adversely affect people's traveling convenience more and more, which has become one of the most crucial factors considered in urban planning and design in recent years. Urban traffic congestion is a severe problem that significantly reduces the quality of life in particularly metropolitan areas. However, frequently constructing new roads is not realistic and untenable in social and economic aspects. In the effort to deal with this intractable problem, so-called intelligent transportation systems (ITS) technologies are successfully implemented widely throughout the world nowadays. ITS with two important components advanced traffic management systems (ATMS) and advanced traveler information systems (ATIS) aim to relieve the increasing congestion and decrease travel time through providing information to the drivers by means of radio broadcasts or dynamic route guidance systems.

The provision of accurate real-time information and predictions of traffic states such as traffic flow, travel time, occupancies, etc., is much fundamental and contributive to the great success of ITS (Chen et al., 2010; Dong et al., 2010; Vlahogianni et al., 2004; Lam et al., 2006; Tan et al., 2009; Tang et al., 2003; Thomas et al., 2010; Zhang \& Liu, 2008, 2009c). As an important part of ITS, traffic states analysis and traffic forecasting are important in directing commuters to pick optimal routes, which have attracted many researchers to focus on this subject in recent decades. In general, as illustrated in the statement, the traffic forecasting "can be separated into two paradigms: the empirical based, incorporating fairly standard statistical methodology on the one hand, and that based on traffic process theory, either of demand or of supply, on the other" (Van Arem et al., 1997).

Because of the feasibility of data collection from numerous kinds of equipments and the requirements of dynamic management, the empirical approaches for traffic forecasting correspond with the development trends of ITS. It aims to find out the hidden regularity of traffic states through the random and uncertain traffic data by systematic analysis and a variety of mathematics/physics methods.

The empirical approaches can be approximately divided into two types: basic forecasts approaches and combined forecasts approaches. The basic forecasts approach means to predict the traffic state using a certain particular prediction model. The robustness and 
accuracy of these approaches lie on the prediction models themselves. Furthermore, basic forecasts approaches can be roughly classified into two types: parametric and nonparametric techniques. Both techniques have shown their own advantages on different occasions in recent years (Tsekeris \& Stathopoulos, 2010; Zhang \& Liu, 2009f, Zhang \& Liu, 2010; Zhang et al., 2010). On the basis of the classification, the chapter provides a systematic review of these models such as historical-mean (HM), filtering algorithm, linear and nonlinear regression, autoregressive process, neural network (NN), fuzzy systems, support vector regression (SVR), and Bayesian networks, etc.

The combined forecasts approach means to combine different forecasts into a single one that is assumed to produce a more accurate forecast. The robustness and accuracy of combined forecast approaches lie not only on the prediction effect of individual prediction model, but also on the efficiency of combination. Because the combined method is to apply each predictor's unique feature to capture different patterns in the data, it would give a smaller error variance than any of the individual methods (Bates \& Granger, 1969). This advantage may make the approach fully scalable to the very large amounts of traffic data practically. Due to its simplicity and practicability, the combined forecasts approach becomes very important to traffic forecasting, and researchers have focused on it, both theoretical and applied.

Though the data-driven traffic forecasting gains many achievements, there still exist some unsolved problems. From the practical point of view, data gained from some detectors are incomplete, i.e., partially or completely missing or substantially contaminated by noises. The missing data sometimes render an entire dataset useless, which is a major hurdle in analyzing traffic information. As missing data treatment is an important preparation step for effective management of ITS, some proper solutions to solve missing data problems are provided in the chapter. And the chapter ends with a brief introdcution of Shanghai Integrated Transportation Information Platform (SITIC), which represents the level of informatization development in transportation.

\section{A brief review of data-driven traffic forecasting}

The data-driven traffic forecasting refers to predicting the future state of a certain transportation system based on the historical data, existing traffic data and the related statistics data (Brockwell \& Davis, 2002; Chrobok, 2004). Traffic forecasting is a branch of forecasting, and it is an important part of modern transportation planning and intelligent transportation system. Usually, traffic flow, average speed and travel time etc., are defined as the basic parameters of traffic state. Specifically, traffic forecasting is essentially the prediction of these basic parameters based on dynamic road traffic time series data. For instance, most of literature foucs on traffc flow forecasting (Jiang \& Adeli, 2004; Qiao et al., 2001; Abdulhai et al., 1999; Castillo et al., 2008; Chen \& Chen, 2007; Dimitriou et al., 2008; Ding et al., 2002; Huang \& Sadek, 2009; Ghosh et al., 2005, 2007; Smith et al., 2002), travel time forecasting, and related analysis such as validation, optimization, etc. (Chan et al., 2003; Chan \& Lam, 2005; Chang et al., 2010; Kwon, 2000; Kwon \& Petty, 2005; Lam, 2008; Lam et al., 2002, 2005, 2008; Lam \& Chan, 2004; Lee et al. 2009; Nath et al., 2010; Schadschneider et al., 2005; Tam \& Lam, 2009; Tang \& Lam, 2001; Yang et al., 2010). 
Overall, the process of traffic state variation is a real-time, nonlinear, high dimensional and non-stationary stochastic process. With the shortening of statistical time range, the stochastic and uncertainty of traffic state are more and more strong. Short-term traffic state variation is not only related to the state of the local road section over the past few hours, but also influenced by the traffic states of upstream and downstream road sections, weather situation and unexpected events, etc.

From the spatial and temporal point of view, the traffic state can reflect regular variation. For example, the traffic states of various road sections of urban road network during peak and non-peak period show periodic variation respectively; and the traffic states in urban highway traffic on weekdays and weekends also show different periodic variation, which reflects the temporal regularity of road network traffic. Meanwhile, the urban road network topology, the length of each road link, lane width and traffic direction, etc. can determine the variation of traffic state on a particular road link, which reflects the spatial regularity of road network traffic. Therefore, in the research of transportation prediction, it is essential to fully consider real-time traffic state variation with the randomness and regularity temporally and spatially. Namely, real-time traffic forecasting should predict the future traffic state on the basis of studying the specific sections of the historical traffic data, the whole spatial-temporal road network traffic condition variation, weather situation, and other influence factors. Fig.1 describes the framework of data-driven traffic forecasting models.

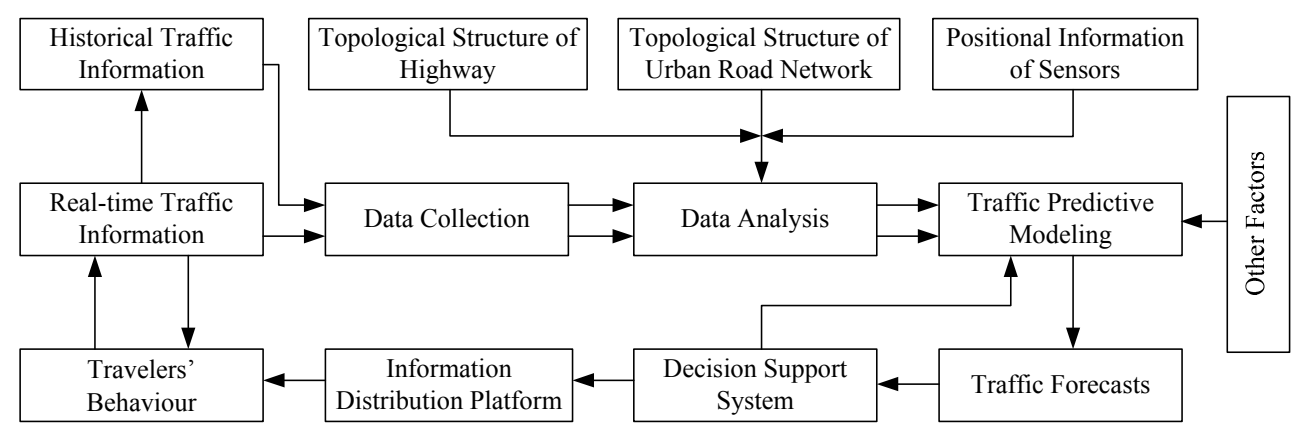

Fig. 1. The framework of traffic forecasting models.

\section{Traffic forecasting approaches}

The following factors are usually used for the classification of traffic forecasting approaches: single road link or transportation network, freeways or urban streets, physical models or mathematical methodologies, univariate or multivariate method, etc. From the methodology point of view, the traffic forecasting approaches can be divided into two types: the empirical based approaches and traffic process theory based approaches. For the convenience of data collection from numerous kinds of equipments, a large amount of the historical traffic information and real-time traffic information can be obtained. And the empirical approaches become the new trend of ITS. In this part, we focus on the achievements concerned with empirical approach according to its classification. 


\subsection{Basic forecasts approaches}

A large amount of scientific literature has been concerned with basic forecasts approaches. On the basis of the classification, the chapter provides a systematic review of parametric and nonparametric traffic forecasting techniques briefly.

\subsubsection{Parametric traffic forecasting approaches}

Since the early 1980s, extensive variety of parametric approaches has been employed ranging from historical average algorithms (Smith \& Demetsky, 1997; Wu et al., 2004), smoothing techniques (Smith \& Demetsky, 1997; Williams et al., 1998), linear and nonlinear regression (Deng et al., 2009; Lu et al., 2009; Zhang \& Rice 2003; Sun et al., 2003), filtering techniques (Ross, 1982; Okutani \& Stephanedes, 1984; Whittaker et al., 1997; Chien \& Kuchipudi, 2003; Stathopoulos \& Karlaftis, 2003), to autoregressive linear processes (Min et al., 2010; Min \& Wynter, 2011). Thereinto, the autoregressive integrated moving average (ARIMA) (Ahmed \& Cook, 1979) family of models such as simple ARIMA (Levin \& Tsao, 1980; Nihan \& Holmesland, 1980; Hamed et al., 1995; Smith, 1995; Williams, 1999), ATHENA (Kirby et al., 1997), subset ARIMA (Lee \& Fambro, 1999), SARIMA family (Smith et al., 2002; Williams et al., 1998, 2003; Ghosh et al., 2005), are classical milestones in forecasting area. Such time series methods belong to time domain approaches, and frequency domain approaches like spectral analysis, "which are regressions on periodic sines and cosines, show their important insights into traffic data which may not apparent in an analysis in the time domain only" (Stathopoulos \& Karlaftis, 2001a, b). The parametric traffic forecasting approach is the milestone of the traditional time series forecasting. And it brings significant developments for traffic forecasting.

\subsubsection{Nonparametric traffic forecasting approaches}

Lately extraordinary development of distinct nonparametric techniques, including nonparametric regression, neural networks, etc., has shown that they may be able to become a high potential alternative to their parametric counterparts (Huisken, 2003; Lam et al., 2006). In essence, nonparametric statistical regression can be regarded as a dynamic clustering model that relies on the relationship between dependent and independent traffic variables. (Davis \& Nihan, 1991; Smith \& Demetsky, 1997; You \& Kim, 2000; Smith et al., 2000, 2002; Clark, 2003; Turochy, 2006). In other words, it attempts to identify past information that are similar to the state at prediction time, which leads to easily implemented nature. Over the past decade, another nonparametric technique, artificial neural networks (ANNs) have been applied in traffic forecasting because of their strong ability to capture the indeterministic and complex nonlinearity of time series (Smith \& Demetsky, 1994, 1997; Chang \& Su, 1995; Dougherty \& Cobbet, 1997; Lam \& Xu, 2000; Park et al., 1999; Dharia \& Adeli, 2003; Wei et al., 2009; Wei \& Lee 2007; Lee, 2009). Motivated by the universal approximation property, neural network models ranging from purely static to highly dynamic structures include the multilayer perceptrons (MLPs) (Clark et al., 1993; Vythoulkas, 1993; Lee \& Fambro, 1999; Gilmore \& Abe, 1995; Ledoux, 1997; Innamaa, 2000; Florio \& Mussone, 1996; Yun et al., 1998; Zhang, 2000; Chen et al., 2001), the radial basis function (RBF) ANNs (Lyons et al., 1996; Park et al., 1998; Park \& Rilett, 1998; Chen et al., 2001), the time-delayed ANNs (Lingras et al., 2000; Lingras \& Mountford, 2001; Yun et al., 1998; Yasdi 1999; Abdulhai et al., 1999; Dia, 2001; Ishak \& Alecsandru, 2003), the recurrent 
ANNs (Dia, 2001; Van Lint et al., 2002, 2005), and the hybrid ANNs (Abdulhai et al., 1999; Chen et al., 2001; Lingras \& Mountford, 2001; Park, 2002; Yin et al., 2002; Vlahogianni et al., 2005; Jiang \& Adeli, 2005; Quek et al., 2006), etc. Besides the above neural networks models, computational intelligence (CI) techniques that encompass fuzzy systems, machine learning and evolutionary computation have been successfully developed in the field of traffic forecasting. For instance, some literature applies Bayesian networks (Zhang et al. , 2004; Castillo et al., 2008) and Bayesian inference based regression techniques (Khan, 2011; Tebaldi et al., 2002; Sun et al., 2005, 2006; Zheng et al., 2006; Ghosh et al., 2007), some literature uses fuzzy systems or fuzzy NNs to predict the traffic states (Dimitriou et al., 2008; Quek et al., 2009). While others start to explore support vector regression (SVR) to model traffic characteristics and produce prediction of traffic states (Castro-Neto, 2009; Ding et al., 2002; Hong, 2011; Hong et al., 2011; Wu et al., 2004; Vanajakshi \& Rilett, 2004). The recent application of different CI techniques and hybrid intelligent systems has shown that the rapidly expanding research field is promising.

\subsection{Combined forecasts approaches}

The basic idea of the combined forecasts approach is to apply each predictor's unique feature to capture different patterns in the data (Zhang \& Liu, 2009d, 2009e). The complement in capturing patterns of data sets is theoretically essential for more accurate prediction (Timmermann, 2005; Huang, 2007). “Both theoretical and empirical findings suggest that combining different methods can be an effective way to improve forecast performances." (Yu et al., 2005a). The linear combining forecasts methodology has a long historical background. Compared to computational intelligence based nonlinear ensemble forecasting models (Chen \& Zhang, 2005; Chen \& Chen, 2007), the linear combination retains the conceptual and computational simplicity. In the part, we focus on the application of linear combination method. Researchers have proposed various combined methods since the pioneering work of Bates and Granger. Clemen provided a review and annotated bibliography of the literature for reference (Clemen, 1989). "Research in various fields has strongly suggested that the performance of prediction can be enhanced when (sometimes even in simple fashion) forecasts are combined." (Yang, 2004).

Basically, we can describe the main problem of combined forecasts as follows. Suppose there are $\mathrm{N}$ forecasts such as $\widehat{V}_{P 1}(t), \widehat{V}_{P 2}(t), \ldots, \widehat{V}_{P \mathrm{~N}}(t)$ (including correlated or uncorrelated forecasts), where $\hat{V}_{P i}(t)$ represents the forecasting result obtained from the $i$ th model during the time interval $t$. The combination of the different forecasts into a single forecast $\widehat{V} P(t)$ is assumed to produce a more accurate forecast. The general form of such a combined forecast can be described with formula

$$
\widehat{V}_{P}(t)=\sum_{i=1}^{\mathrm{N}} w_{i} \widehat{V}_{P i}(t)
$$

where $w_{i}$ denotes the assigned weight of $\hat{V}_{P i}(t)$, and commonly the sum of the weights is equal to one, i.e., $\sum_{i} w_{i}=1$. Our studies mainly investigate the combined models with the additional restriction that no individual weight can be outside the interval $[0,1]$. Various methods can be applied to determine the weights used in the combined forecasts. Four common methods are presented in the following. 


\subsubsection{Equal Weights (EW) methods}

The EW method, applying a simple arithmetic average of the individual forecasts, is a relatively robust method with low computational efforts. Namely, each $w_{i}$ is equal to $1 / \mathrm{N}$ $(i=1,2, \ldots, N)$, where $\mathrm{N}$ is the number of forecasts. The beauty of using the simple average is that it is easy to understand and implement, not requiring any estimation of weights or other parameters (Jose \& Winkler, 2008). This makes it robust because they are not sensitive to estimation errors, which can sometimes be substantial. It often provides better results than more complicated and sophisticated combining models (Clemen, 1989). Although the approach has non-optimal weights, it may give rise to better results than time-varying weights that are sometimes adversely affected by some unsystematic changes over time. Under the circumstances, the method has the virtues of impartiality, robustness and a good "track-record" in time series forecasting. It has been consistently the choice of many researchers in the combination of forecasts.

\subsubsection{Optimal Weights (OW) methods}

Bates \& Granger proposed that using a MV criterion can determine the weights to adequately apply the additional information hidden in the discarded forecast(s) (Bates \& Granger, 1969), and Dickinson extended the method to the combinations of $\mathrm{N}$ forecasts (Dickinson, 1973). Assuming that the individual forecast errors are unbiased, we can calculate the vector of weights to minimize the error variance of the combination according to the formula

$$
\boldsymbol{w}=\boldsymbol{M}_{V}^{-1} \mathbf{I}_{n}\left(\mathbf{I}_{n}^{\prime} \boldsymbol{M}_{V}^{-1} \mathbf{I}_{n}\right)^{-1}
$$

where $\mathbf{I}_{n}$ is the $n \times 1$ matrix with all elements unity (i.e. $n \times 1$ unit vector) and $\boldsymbol{M}_{V}$ is the covariance matrix of forecast errors (e.g. $M_{V i j}$ is the covariance between the error of forecast $i$ and forecast $j$ at a particular point in time). Granger \& Ramanathan pointed that the method is equivalent to a least squares regression in which the constant is suppressed and the weights are constrained to sum to one (Granger \& Ramanathan, 1984). In the case of a combination of two forecasts, we suppose there is no correlation between forecast errors.

\subsubsection{Minimum Error (ME) methods}

The ME method minimizes the forecasting errors when combining individual forecasts into a single one. A solution for this method applies linear programming (LP) whose principle and computational process are described as follows (Yu et al., 2005a). Set the sum of absolute forecasting error (i.e., $\sum_{i} E_{i}(t)$ during the time interval $t$ ) as

$$
F_{L P}=\sum_{i=1}^{\mathrm{N}}\left|E_{i}(t)\right|=\sum_{i=1}^{\mathrm{N}}\left|w_{i}(t)\left(\widehat{V}_{P i}(t)-V_{O}(t)\right)\right| \quad t=1,2, \cdots, \mathrm{T}
$$

where $F_{L P}$ is the objective function of $L P ; V_{O}(t)$ denotes the observed value during the time interval $t$ and $\mathrm{T}$ the number of forecasting periods. To eliminate the absolute sign of the objective function, assume that

$$
u_{i}(t)=\frac{\left|E_{i}(t)\right|+E_{i}(t)}{2}=\left\{\begin{array}{cc}
E_{i}(t), & E_{i}(t) \geq 0 \\
0, & E_{i}(t)<0
\end{array}\right.
$$




$$
v_{i}(t)=\frac{\left|E_{i}(t)\right|-E_{i}(t)}{2}=\left\{\begin{array}{cc}
0, & E_{i}(t) \geq 0 \\
-E_{i}(t) & E_{i}(t)<0
\end{array}\right.
$$

The introduction of $u_{i}(t)$ and $v_{i}(t)$ aims to transform the absolute sign of the objective function so as to be consistent with the standard form of LP. Obviously, $\left|e_{i}(t)\right|=u_{i}(t)+v_{i}(t)$, $e_{i}(t)=u_{i}(t)-v_{i}(t)$. On the basis of the above specification, the LP model can be constructed as follows:

$$
\left\{\begin{array}{l}
\operatorname{Min} O=\sum_{i=1}^{\mathrm{N}}\left(u_{i}(t)+v_{i}(t)\right), \\
\sum_{i=1}^{\mathrm{N}} w_{i}(t)\left(\widehat{V}_{P i}(t)-V_{O}(t)\right)-u_{i}(t)+v_{i}(t)=0, \\
\sum_{i=1}^{\mathrm{N}} w_{i}(t)=1, \\
w_{i}(t) \geq 0, u_{i}(t) \geq 0, v_{i}(t) \geq 0, i=1,2, \cdots, \mathrm{N}, t=1,2, \cdots, \mathrm{T}
\end{array}\right.
$$

where $i$ denotes the number of individual forecasts, and $t$ represents the forecasting periods. In the equation group, assuming $w_{i} \geq 0$ aims to make every forecast method contribute to the combined forecasting results. The ME method is equivalent to a simple dynamic linear programming problem; thus, the optimal solutions to the LP can be obtained by the simplex algorithm. The method is an effective combination methodology with time-variant weights.

\subsubsection{Minimum Variance (MV) methods}

The linear combining forecasts methodology has a long historical background. Researchers

Since the negative value of the weight has no factual meaning, researchers usually add the restriction that no individual weight can be outside the interval $[0,1]$ practically. The main ideas are described as

$$
\left\{\begin{array}{l}
\operatorname{Min}\left(w_{i} \boldsymbol{M}_{V} w_{i}^{\mathrm{T}}\right) \\
\sum_{i=1}^{\mathrm{N}} w_{i}=1, \quad i=1,2, \cdots, \mathrm{N} \\
w_{i} \geq 0
\end{array}\right.
$$

where $\boldsymbol{M}_{V}$ is the matrix of error variance. By solving the quadratic programming $(\mathrm{QP})$ problems, an optimal weight set can be obtained for the combining forecasts ( $\mathrm{Yu}$ et al., 2005b). The problem with this optimizing approach is that it still requires $\boldsymbol{M}_{V}$ to be properly estimated. Practically, $\boldsymbol{M}_{V}$ is often not stationary, in which case it is estimated on the basis of a short history of forecasts and thus the method becomes an adaptive approach to combining forecasts (De Menezes et al., 2000).

\section{Data imputation}

Various imputation techniques have been developed in the past decade. Techniques including naïve imputation, expectation maximization (EM) algorithm (Schafer, 1997; Dempster et al., 1977), data augmentation (DA) algorithm (Tanner \& Wong, 1987), and regression imputation, etc. lead logically to modern approaches. Regression imputation and MI have been proved to 
be more effective than the others, especially the latter one (Ni et al., 2005; Zhong et al., 2004). State space methodology is found to be extremely significant to ensure more accurate results in nearest nonparametric regression (Kamarianakis \& Prastakos, 2005). The amelioration including the historical information in the state space may further improve imputation accuracy. Zhang \& Liu proposed LS-SVMs method incorporating with the multivariate state space approach to recover missing traffic flow data in arterial streets of Xuhui district, Shanghai (Zhang \& Liu, 2009a, 2009b). The state space not only incorporates lagged values but also is supplemented with aggregate measures such as historical information, spatial information, etc. Fully applying spatial and temporal information, the state space based approaches can model the traffic flow successfully. In this part, we focus on the imputation techniques based on state space method (Zhang \& Liu, 2009a, 2009b).

In time series, state is defined as a series of system values measured during the past $k$ intervals $(k \in \mathrm{N})$. Measurements at time $t, t-1, \ldots, t-k$ compose a state vector and $k$ is an appropriate number of lags. A state vector of traffic flow measured by loop detector(s) $l$ every $F$ minute(s) can be described by:

$$
\boldsymbol{X}_{l}\left(t, k_{l}\right)=\left[V_{l}(t), V_{l}(t-1), \cdots, V_{l}\left(t-k_{l}\right)\right]
$$

where $V_{l}(t)$ denotes the traffic flow from the detector(s) $l$ during the time interval $t ; V_{l}(t-1)$ represents the traffic flow from the detector(s) $l$ during the previous $F$-minute interval, etc. If $L$ loop detectors are considered around the object detector(s) in the traffic network, the values of $l$ range from 1 to $L(L \in \mathrm{N})$. When $t \leq k_{l}, X_{l}\left(t, k_{l}\right)$ contains the last $k_{l}-t+1$ parameters measured in theday before the chosen particular day. Object detector(s) can be defined as the detector(s) with missing data.

Considering the historical information in the past week(s), the state space $\boldsymbol{X}(t, L)$ can be defined as:

$$
\boldsymbol{X}(t, L)=\left[\boldsymbol{X}_{1}\left(t, k_{1}\right), \boldsymbol{X}_{2}\left(t, k_{2}\right), \cdots, \boldsymbol{X}_{\mathrm{L}}\left(t, k_{\mathrm{L}}\right), V_{\mathrm{G} h i s t, w}(t)\right]
$$

where $V_{\text {Ghist,w }}(t)$ is the historical traffic flow from the object detector(s) at the time-of-day and day-of-the-week associated with time interval $t$ at week $w$ that is usually selected as the previous week. The selection of appropriate $L$ and $k_{l}$ for each detector $l$ is based on the spatio-temporal analysis of traffic flows collected from loop detectors at different intersections. Input-output pairs for the training process can apply the vectors

$$
\left\{\boldsymbol{X}(t, L), V_{\mathrm{G}}(t)\right\}, t \in\left[k_{\max }, \mathrm{T}\right], k_{\max }=\max \left(k_{1}, k_{2}, \cdots, k_{\mathrm{L}}\right)
$$

where $V_{G}(t)$ is the traffic flow obtained from the object detector(s) $G$ during the time interval $t$; $\mathrm{T}$ is the number of time intervals in a day; $k_{\max }$ denotes the maximum value among the lags $k_{l}, l=1,2, \ldots, L$. This training process must suppose the good condition of detector(s) $G$ and close relation between $V_{G}(t)$ and $V_{l}(t)$. The total number of training samples is $\left(\mathrm{T}-k_{\max }+1\right)$. When detector(s) $G$ cannot supply complete data $V_{G}(\mathrm{~T}+h)$ at time $\mathrm{T}+h, h \in \mathrm{N}$, due to some malfunctions, vectors $X(T+h, L)$ are used as input variables to obtain the predicted results $\widehat{V}_{G}(\mathrm{~T}+h)$ that can replace the missing values. Comparison between the imputed values and the actual ones $V_{G}(\mathrm{~T}+h)$ can be utilized to verify the efficiency of different imputation methods. 


\section{A brief review of Shanghai integrated transportation information platform}

In recent years, we have been exploring traffic informatization and building Shanghai Integrated Transportation Information Platform (SITIC) that provides a mechanism to connect isolated islands of information. After three periods of construction, the system software/hardware, backbone networks, information distribution channels have been completed successfully. The guiding thought for the development of SITIC is "Investigating the present state, revealing the objective laws, and guiding the urban transport more scientifically and efficiently".

Classifying the transportation into Road Traffic, Public Traffic, Inter-city Traffic and District/Transport Hub, sorts of information of vehicles and people were collected from kinds of sources, which is the basis of the normal running of SITIC and further data mining. Different real-time information on the transportation of Shanghai can be clearly shown in SITIC. Researching the transportation problems in metropolis, especially the traffic prediction, we found that mastering the situation of transportation is important to traffic management, which leads to the essentiality of level division of the road network into macro (network), meso (district), and micro (link) levels. Meanwhile, data gained from some detectors are incomplete, i.e., partially or completely missing or substantially contaminated by noises. This may be caused by malfunctions in data collection and recording systems that often occur in practice. The missing data sometimes render an entire dataset useless, which is a major hurdle in analyzing traffic information. Missing data treatment is another important preparation step for effective management of intelligent transportation systems (ITS). The following figure describes the contents and function of the platform briefly.

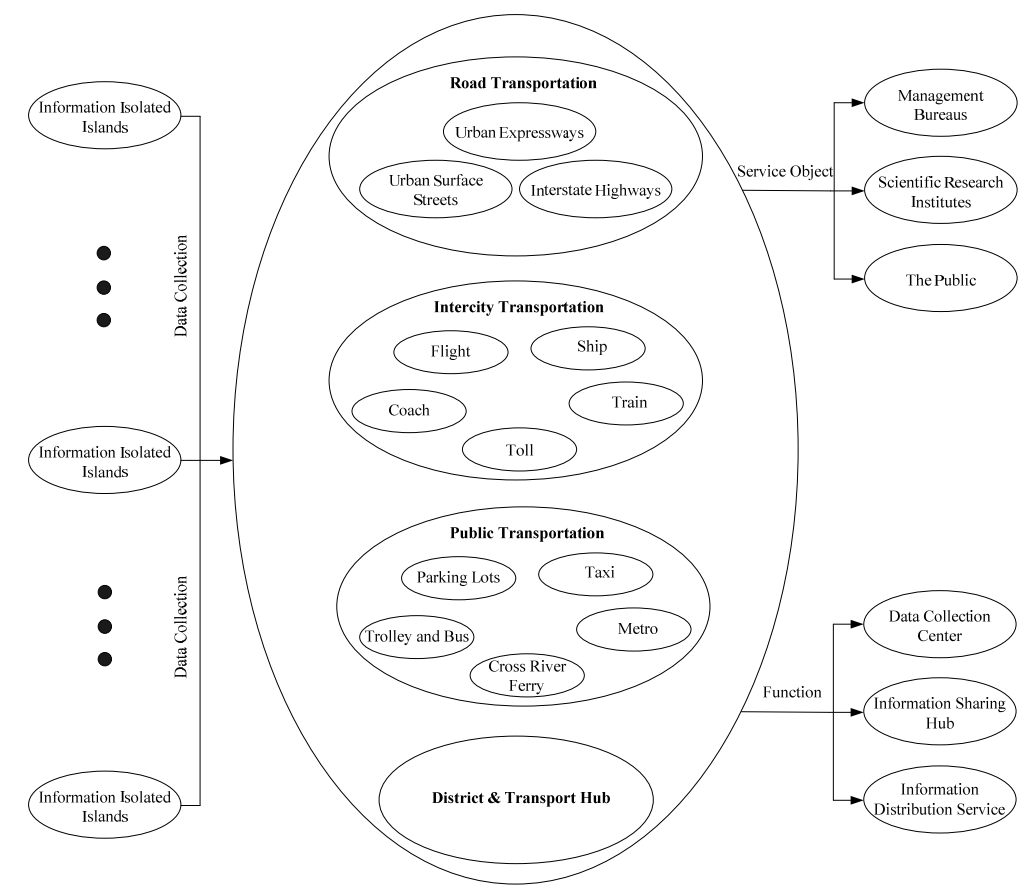

Fig. 2. The main structure of SITIC. 


\section{Conclusion}

The chapter summarizes data driven approaches for traffic prediction in three parts. First, on the basis of classification of the main methods for traffic forecasting, the chapter aims to describe a large amount of literature of traffic forecasting models. And we focus on the decription of combined forecasts approaches that we believe represent the trend of the development of traffic forecasting in practice. Second, from the practical point of view, proper solutions to solve missing data problems are decribled, espertially the state space based approaches. Finally, from the perspective of dynamic traffic management, it presents the corresponding work and experience of traffic informatization in Shanghai.

\section{References}

Abdulhai, B.; Porwal, H.; \& Recker, W. (1999). Short-term freeway traffic flow prediction using genetically optimized time-delay-based neural networks, Proc. 78th TRB Annual Meeting, Washington, D.C

Ahmed, M. S. \& Cook, A. R. (1979). Analysis of freeway traffic time-series data by using Box-Jenkins techniques, Transportation Research Record. 722, Transportation Research Board, Washington, D.C., pp. 1-9

Bates, J. M. and Granger, C. W. J. (1969). The combination of forecasts, Oper. Res. Quarterly., Vol.20, No.4, pp. 451-468

Brockwell, P. J. \& Davis, R. A. (2002). Introduction to Time Series and Forecasting, SpringerVerlag, New York

Castillo,E.; Menéndez,J.M. \& Cambronero,S.S. (2008). Predicting traffic flow using Bayesian networks, Transportation Research Part B: Methodological., Vol.42, No.5, pp. 482-509

Castro-Neto M., Jeong Y. S., Jeong M. K., \& Han L.D. (2009). Online-SVR for short-term traffic flow prediction under typical and atypical traffic conditions, Expert Systems with Applications, Vol. 36, No. 3, pp. 6164-6173

Chan, K.S.; Lam, W. H. K. \& Xu, G. (2003). A Case Study on Short-term Travel Time Forecasting in Hong Kong, Proceedings of the 8th Conference of Hong Kong Society for Transportation Studies, Hong Kong, 13-14 December, pp. 444-451

Chan, K.S. \& Lam, W. H. K. (2005). On-line Travel Time Forecasts for Real-time Traveller Information System in Hong Kong, Proceedings of the 10th International Conference of Hong Kong Society for Transportation Studies, 10 December, Hong Kong, pp. 94-102

Chang, G. L., and Su, C. C. (1995). "Predicting intersection queue with neural network models, Transp. Res., Part C: Emerg. Technol., Vol.3, No.3, pp. 175-191

Chang, J.; Chowdhury, N. K. \& Lee H. (2010). New travel time prediction algorithms for intelligent transportation systems, Journal of Intelligent \& Fuzzy Systems: Applications in Engineering and Technology, Vol.21, No.1-2, pp. 5-7

Chen, H. B, Grant-Muller, S., Mussone, L., and Montgomery, F. (2001). A study of hybrid neural network approaches and the effects of missing data on traffic forecasting, Neural Comput. \& Applic. Vol.10, No.3, pp. 277-286

Chen, D. W. \& Zhang, J. P. (2005). Time series prediction based on ensemble ANFIS, Proc. Int. Conf. Machine Learning and Cybernetics., Vol. 6, pp. 3552-3556

Chen, L. \& Chen, C. L. P. (2007). Ensemble learning approach for freeway short-term traffic flow prediction, Proc. IEEE Int. Conf. Sys. of Sys. Eng., pp. 1-6 
Chen, S.Y.; Wang, W. \& Zuylen, H.V. (2010). A comparison of outlier detection algorithms for ITS data, Expert Systems with Applications,Vol.37, No.2, pp. 1169-1178

Chien S. I. J. \& Kuchipudi C. M., (2003). Dynamic travel time prediction with real-time and historic data, J. Transp. Eng., Vol.129, No.6, pp. 608-616

Chrobok, R.; Kaumann, O.; Wahle, J. \& Schreckenberg, M. (2004). Different methods of traffic forecast based on real data, Eur. J. Oper. Res. Vol.155, No.3, pp. 558-568

Clark, S. D.; Dougherty, M. S. \& Kirby, H. R. (1993). The use of neural networks and time series models for short-term traffic forecasting: a comparative study, Proc. 21st Summer Annual Meeting, PTRC, Manchester, UK

Clark, S. (2003). Traffic prediction using multivariate nonparametric regression, J. Transp. Eng., Vol.129, No.2, pp. 161-168

Clemen, R. T. (1989). Combining forecasts: a review and annotated bibliography, Int. J. Forecast., Vol.5, pp. 559-583

Davis, G. A. \& Nihan, N. L. (1991). Nonparametric regression and short-term freeway traffic forecasting, J. Transp. Eng., Vol.117, No.2, pp. 178-188

De Menezes, L. M.; Bunn, D. W. \& Taylor, J. W. (2000). Review of guidelines for the use of combined forecasts, Eur. J. Oper. Res., Vol.120, pp. 90-204

Dempster, A. P.; Laird, N. M. \& Rubin, D. B. (1977). Maximum-likelihood estimation from incomplete data via the EM algorithm, J. Royal Statist. Soc., Series B., Vol. 39, pp. $1-38$

Deng, S.; Hu J. M.; Wang Y., \& Zhang, Y. (2009). Urban road network modeling and realtime prediction based on householder transformation and ajacent vector, Lecture Notes in Computer Science, Vol. 5553, pp. 899-908

Dharia, A. \& Adeli, H. (2003). Neural network model for rapid forecasting of freeway link travel time, Eng. Applic. Artif. Intell., Vol.16, No.7-8, pp. 607-613

Dia, H. (2001). An object-oriented neural network approach to short-term traffic forecasting, Eur. J. of Oper. Res. Vol.131, No.2, pp. 253-261

Dimitriou,L.; Tsekeris, T. \& Stathopoulos,A., (2008). Adaptive hybrid fuzzy rule-based system approach for modeling and predicting urban traffic flow, Transportation Research Part C: Emerging Technologies., Vol.16, No.5, pp. 554-573

Dickinson, J. P. (1973). Some statistical results in the combination of forecasts, Oper. Res. Quarterly, Vol.24, No.2, pp. 253-260

Ding, A.; Zhao X. \& Jiao, L. (2002). Traffic flow time series prediction based on statistics learning theory." Proc. IEEE 5th Int. Conf. Intell. Transp. Syst., pp. 727-730

Dong, S.; Li, R. M.; Sun, L. G., Chang, T. H.; \& Lu, H. P. (2010). Short-term traffic forecast system of Beijing, Journal of the Transportation Research Board, Vol. 2193, pp. 116-123

Dougherty, M. S. \& Cobbet, M. R. (1997). Short-term inter-urban traffic forecasts using neural networks, Int. J. Forecast., Vol.13, pp. 21-31

Florio, L. \& Mussone, L. (1996). Neural network models for classification and forecasting of freeway traffic flow stability, Control Eng. Pract., Vol.4, No.2, pp. 153-164

Ghosh, B.; Basu, B. \& O'Mahony, M. M. (2005). Time-series modelling for forecasting vehicular traffic flow in Dublin, Proc. 85th TRB Annual Meeting, Washington, D.C.

Ghosh, B.; Basu, B. \& O’Mahony, M. M. (2007). Bayesian time-series model for short-term traffic flow forecasting, J. Transp. Eng., Vol.133, No.3, pp. 180-189

Gilmore, J. E. \& Abe, N. (1995). Neural network models for traffic control and congestion prediction, IVHS J., Vol.2, No.3, pp. 231-252 
Granger, C. W. J. \& Ramanathan, R.(1984). Improved methods of forecasting, J. Forecast., Vol. 3, pp. 197-204

Hamed, M. M., Al-Masaeid, H. R., and Said, Z. M. B. (1995). “Short-term prediction of traffic volume in urban arterials." J. Transp. Eng., Vol.121, No.3, pp. 249-254

Hong, W. C. (2011). Traffic flow forecasting by seasonal SVR with chaotic simulated annealing algorithm, Neurocomputing, Vol. 74, No. 12-13, pp. 2096-2107

Hong, W.C.; Dong, Y.C.; Zheng, F.F. \& Wei, S.Y. (2011). Hybrid evolutionary algorithms in a SVR traffic flow forecasting model, Applied Mathematics and Computation, Vol.217, No.15, pp. 6733-6747

Huang, H. (2007). Essays on combination of forecasts, Doctoral dissertation, Graduate Program in Economics, University of California, Riverside

Huang, S. \& Sadek, A.W. (2009). A novel forecasting approach inspired by human memory: The example of short-term traffic volume forecasting, Transportation Research Part C: Emerging Technologies, Vol.17, No.5, pp. 510-525

Huisken, G. (2003). Soft-computing techniques applied to short-term traffic flow forecasting, Systems Analysis Modelling Simulation, Vol.43, No.2,pp. 165-173

Innamaa, S. (2000). Short-term prediction of traffic situation using MLP-Neural Networks, Proc. 7th World Cong. Intell. Transp. Syst., Turin, Italy

Ishak, S. \& Alecsandru, C. (2003). Optimizing traffic prediction performance of neural networks under various topological, input, and traffic condition settings, Proc. 82nd TRB Annual Meeting, Washington, D.C.

Jiang, X. M. \& Adeli, H. (2004). Wavelet Packet-Autocorrelation Function Method for traffic flow pattern analysis, Comput.-Aided Civ. \& Inf. Eng., Vol.19, pp. 324-337

Jiang, X. M. \& Adeli, H. (2005). Dynamic wavelet neural network model for traffic flow forecasting, J. Transp. Eng., Vol.131, No.10, pp. 771-779

Jose, V. R. R. \& Winkler, R. L. (2008). Simple robust averages of forecasts: some empirical results, Int. J. Forecast., Vol.24, pp. 163-169

Kamarianakis, Y. \& Prastakos, P. (2003). Forecasting traffic flow conditions in an urban network: Comparison of multivariate and univariate approaches, Proc. 82nd TRB Annual Meeting, Washington, D.C.

Kamarianakis, Y. \& Prastakos, P. (2005). Space-time modeling of traffic flow, Computers $\mathcal{E}$ Geosciences, Vol.31, No.2, pp. 119-133

Khan, A. M. (2011), Bayesian predictive travel time methodology for advanced traveller information system, Journal of Advanced Transportation, 45: n/a. doi: 10.1002/atr.147

Kirby, H. R.; Watson, S. M.\& Dougherty, M. S. (1997). Should we use neural network or statistical models for short-term motorway traffic forecasting? Int. J. Forecast., Vol.13, No.1, pp. 43-50

Kwon, J.; Coifman, B. \& Bickel, P. (2000). Day-to-Day Travel Time Trends and Travel Time Prediction from Loop Detector Data, Transportation Research Record. 1717, TRB, pp. 120-129

Kwon, J. \& Petty, K. (2005). A Travel Time Prediction Algorithm Scalable to Freeway Networks with Many Nodes with Arbitrary Travel Routes, Transportation Research Record. 1935, TRB, pp. 147-153

Lam, W. H. K. \& Xu, J. (2000). Estimation of AADT from short period counts in Hong Kong-A comparison between neural network method and regression analysis, $J$. Adv. Transp., Vol. 34, No. 2, pp. 249-268 
Lam, W. H. K.; Chan K.S. \& Shi, J.W.Z. (2002). A Traffic Flow Simulator for Short-term Travel Time Forecasting, Journal of Advanced Transportation, Vol. 36, No. 3, pp. 231242

Lam, W. H. K. \& Chan, K.S. (2004). Short-term forecasting of travel time and reliability, Proceedings of the International Workshop on Behavior in Networks, ed. Seungjae Lee, William H.K. Lam and Yasuo Asa, July 22-23, The University of Seoul, Seoul, Korea, pp. 127-135

Lam, W. H. K.; Chan, K.S.; Tam, M.L. \& Shi, J. W. Z. (2005). Short-term Travel Time Forecasts for Transport Information System in Hong Kong, Journal of Advanced Transportation, Vol. 39, No. 3, pp. 289-305

Lam, W. H. K.; Tang, Y. F.; Chan, K. S. \& Tam, M. L. (2006). Short-term hourly traffic forecasts using Hong Kong annual traffic census, Transp., Vol. 33, No. 3, pp. 291-310

Lam, W. H. K.; Tang, Y. F. \& Tam, M. L. (2006). Comparison of two non-parametric models for daily traffic forecasting in Hong Kong, Int. J. Forecast., Vol. 25, No. 3, pp. 173-192

Lam, W. H. K. (2008). Short-term Forecasting of Travel Times for Hong Kong Incident Management, Proceedings of the ITS Hong Kong Forum 2008 - Incident Management System (IMS) Technologies and Applications, 24 September, Hong Kong, pp. 35-50

Lam, W. H. K.; Tam, M.L.; Sumalee, A.; Li, C.L.; Chen, W.; Kwok, S.K.; Li, Z.L. \& E.W.T. (2008). Ngai Incident Detection based on Short-term Travel Time Forecasting, Proceedings of the 13th International Conference of Hong Kong Society for Transportation Studies, 13-15 December, Hong Kong, pp. 83-92

Ledoux, C. (1997). An urban traffic flow model integrating neural networks, Transp. Res., Part C: Emerg. Technol., Vol. 5, No. 5, pp. 287-300

Lee, S. \& Fambro, D. B. (1999). Application of subset autoregressive integrated moving average model for short-term freeway traffic volume forecasting, Transportation Research Record. 1678, TRB, pp. 179-188

Lee, W. H., Tseng, S. S. \& Tsai, S. H. (2009). A knowledge based real-time travel time prediction system for urban network, Expert Systems with Applications, Vol. 36, No. 3, Part 1, pp. 4239-4247

Lee, Y. (2009). Freeway travel time forecast using artificial neural networks with cluster method, Proc. of the 12th International Conference on Information Fusion, Seattle, pp: 1331-1338

Levin, M. \& Tsao, Y. D. (1980). On forecasting freeway occupancies and volumes,Transportation Research Record. 773, TRB, Washington, D.C., pp. 47-49

Lingras, P.; Sharma, S.C. \& Osborne, P. (2000). Traffic volume time-series analysis according to the type of road use, Comput.-Aided Civ. \& Inf. Eng., Vol. 15, No. 5, pp. 365-373

Lingras, P. \& Mountford, P. (2001). Time delay neural networks designed using genetic algorithms for short-term inter-city traffic forecasting, LNAI 2070, IEA/AIE, Vienna, pp.290-299

Lu,Y.; Hu, J.M.; Xu, J. \& Wang, S.N. (2009). Urban Traffic Flow Forecasting Based on Adaptive Hinging Hyperplanes, Proceedings of the International Conference on Artificial Intelligence and Computational Intelligence, pp. 658-667

Lyons, G. D.; McDonald, M.; Hounsell, N. B.; Williams, B.; Cheese, J. \& Radia, B. (1996). Urban traffic management: the viability of short-term congestion forecasting using artificial neural networks, Proc. 24th European Transport Forum, PTRC, pp.1-12 
Min W., \& Wynter L. (2011). Road traffic prediction with spatial-temporal correlations, Transportation Research Part C: Emerging Technologies, Vol. 19, No. 4, pp. 606-616

Min X. Y.; Hu, J. M.; \& Zhang, Z. (2010). Urban traffic network modeling and short-term traffic flow forecasting based on GSTARIMA model, The 13th International IEEE Conference on Intelligent Transportation Systems, pp: 1535-1540

Nath,R.P.D.; Lee,H.J.; Chowdhury, N.K. \& Chang J.W. (2010). Modified K-means clustering for travel time prediction based on historical traffic data, Proceedings of the 14th international conference on Knowledge-based and intelligent information and engineering systems, PP. 511-521

Neto,M.C.; Jeong,Y.S.; Jeong,M.K. \& Han, L.D. (2009). Online-SVR for short-term traffic flow prediction under typical and atypical traffic conditions, Expert Systems with Applications, Vol. 36, No. 3, pp. 6164-6173

Ni, D. H.; Leonard II, J. D.; Guin, A. \& Feng, C. X. (2005). Multiple imputation scheme for overcoming the missing values and variability issues in ITS data, ASCE J. Transp. Eng., Vol. 131, No. 12, pp. 931-938

Nihan, N. L. \& Holmesland, K. O. (1980). Use of the Box and Jenkins time series technique in traffic forecasting, Transportation, Vol. 9, No. 2, pp. 125-143

Okutani, I. \& Stephanedes, Y. J. (1984). Dynamic prediction of traffic volume through Kalman filtering theory, Transp. Res., Part B: Methodol., Vol. 18, No. 1, pp. 1-11

Park, B. (2002). Hybrid neuro-fuzzy application in short-term freeway traffic volume forecasting, Transportation Research Record. 1802, TRB, Washington, D.C., pp. 190-196

Park, B.; Messer, C. J. \& Urbanik, T., II. (1998). Short-term freeway traffic volume forecasting using radial basis function neural network, Transportation Research Record. 1651, TRB, Washington, D.C., pp. 39-47

Park, D. \& Rilett, L. R. (1998). Forecasting multiple-period freeway link travel times using modular neural networks, Transportation Research Record. 1617, TRB, pp. 63-70

Park, D.; Rilett, L. R. \& Han, G. (1999). Spectral basis neural networks for real-time travel time forecasting, J. Transp. Eng., Vol. 125, No. 6, pp. 515-523

Qiao, F.; Yang, H. \& Lam, W. H. K. (2001). Intelligent Simulation and Prediction of Traffic Flow Dispersion, Transportation Research-A, Vol. 35, No. 9, pp. 843-863

Quek, C.; Pasquier, M. \& Lim, B. B. S. (2006). POP-TRAFFIC: A novel fuzzy neural, approach to road traffic analysis and prediction, IEEE Trans. Intell. Transp. Syst., Vol. 7, No. 2, pp. 133-146

Quek, C.; Pasquier, M. \& Lim, B. (2009). A novel self-organizing fuzzy rule-based system for modelling traffic flow behaviour, Expert Systems with Applications., Vol. 36, No. 10, pp. $12167-12178$

Rice, J. \& Van Zwet, E. (2004). A simple and effective method for predicting travel times on freeways, IEEE Trans. Intell. Transp. Syst., Vol.5, No.3, pp. 200-207

Ross, P. (1982). Exponential filtering of traffic data, Transportation Research Record. 869, TRB, Washington, D.C., pp. 43-49

Schadschneider, A.; Wolfgang Knospe, W.; Santen, L. \& Schreckenberg,M. (2005). Optimization of highway networks and traffic forecasting, Physica A: Statistical Mechanics and its Applications, Vol.346, No.1-2, pp. 165-173

Schafer, J. L. (1997). Analysis of Incomplete Multivariate Data. New York: Chapman \& Hall

Smith, B. L. (1995). Forecasting freeway traffic flow for intelligent transportation system applications, Doctoral dissertation. Department of Civil Engineering, University of Virginia, Charlottesville 
Smith, B. L. \& Demetsky, M. J. (1994). Short-term traffic flow prediction: Neural network approach, Transportation Research Record. 1453, TRB, Washington, D.C., pp. 98-104

Smith, B. L. \& Demetsky, M. J. (1997). Traffic flow forecasting: Comparison of modeling approaches, J. Transp. Eng., Vol.123, No.4, pp. 261-266

Smith, B. L.; Williams, B. M. \& Oswald, R. K., (2000). Parametric and nonparametric traffic volume forecasting, Proc. Transportation Research Board Annual Meeting, TRB, Washington, D.C., Reprint 00-817

Smith, B. L.; Williams, B. M. \& Oswald, R. K. (2002). Comparison of parametric and nonparametric models for traffic flow forecasting, Transp. Res., Part C: Emerg. Technol., Vol.10, No.4, pp. 03-321

Stathopoulos, A. \& Karlaftis, M. G. (2001a). Temporal and spatial variations of real-time traffic data in urban areas, Transportation Research Record. 1768, TRB, pp. 135-140

Stathopoulos, A. \& Karlaftis, M. G. (2001b). Spectral and cross-spectral analysis of urban traffic flows, Proc. 4th IEEE Conf. Trans. Intell. Transp. Syst., Oakland, CA, pp. 820-825

Stathopoulos, A. \& Karlaftis, M. G. (2003). A multivariate state-space approach for urban traffic flow modeling and prediction, Transp. Res., Part C: Emerg. Technol., Vol.11, No.2, pp. 21-135

Sun, H.; Liu, H. X.; Xiao, H.; He, R. R. \& Ran, B. (2003). Short-term traffic forecasting using the local linear regression model, Proc. 82nd TRB Annual Meeting, Washington, D.C

Sun, S. L \& Zhang, C. S. (2007). The selective random subspace predictor for traffic flow forecasting, IEEE Trans. Intell. Transp. Syst., Vol.8, No.2, pp. 367-373

Sun, S. L.; Zhang, C. S. \& Yu, G. Q. (2006). A Bayesian network approach to traffic flow forecasting, IEEE Trans. Intell. Transp. Syst., Vol.7, No.1, pp. 124-132

Sun, S. L.; Zhang, C. S. \& Zhang, Y. (2005). Traffic flow forecasting using a spatio-temporal Bayesian network predictor, Lect. Notes Comput. Sci., Vol.3697, pp. 273-278

Tan, M.C.; Wong, S.C.; Xu, J.M.; Guan, Z.R. \& Zhang, P. (2009). An aggregation approach to short-term traffic flow prediction, IEEE Transactions on Intelligent Transportation Systems, Vol. 10, No. 1, pp 60-69

Tang, Y.F. \& Lam, W. H. K. (2001). Validation of Short-term Prediction for Annual Average Daily Traffic in Hong Kong, Proceedings of the 6th Conference of Hong Kong Society for Transportation Studies, Sheraton Hotel, Hong Kong, 1 December, pp. 141-151.

Tang, Y.F. Lam, W. H. K. \& Ng, P. L. P. (2003). Comparison of Four Modeling Techniques for Short-term AADT Forecasting in Hong Kong, ASCE Journal of Transportation Engineering, Vol. 129, No. 3, pp 271-277

Tam, M.L. \& Lam, W. H. K. (2009). Short-Term Travel Time Prediction for Congested Urban Road Networks, Proceedings of the 88th Transportation Research Board Annual Meeting, 11-15 January, Washington D.C., U.S.A., Paper no. 09-2313

Tanner, M. A. \& Wong, W. H. (1987). The calculation of posterior distributions by data augmentation, J. Amer. Stat. Assoc., Vol. 82, pp. 528-550

Tebaldi, C.; West, M. \& Karr, A. F. (2002). Statistical analysis of freeway traffic flows, Int. J. Forecast., Vol.21, No.1, pp. 39-68

Timmermann, A. (2006). Forecast combinations, Handbook of Economic Forecast., Amsterdam: Elsevier, pp. 135-196

Thomas, T.; Weijermars, W. \& Berkum, E.V. (2010). Predictions of urban volumes in single time series, IEEE Transactions on Intelligent Transportation Systems, Vol.11, No.1, pp. $71-80$ 
Tsekeris, T., \& Stathopoulos, A. (2010). Short-term prediction of urban traffic variability: stochastic volatility modeling approach, ASCE Journal of Transportation Engineering, Vol. 136, No. 7, pp. 606-613

Turochy, R. E. (2006) Enhancing short-term traffic forecasting with traffic condition information, J. Transp. Eng., Vol.132, No.6, pp. 469-474

Van Arem, B.; Kirby, H. R.; Van Der Vlist, M. J. M. \& Whittaker, J. C. (1997). "Recent advances and applications in the field of short-term traffic forecasting." Int. J. Forecast., Vol.13, No.1, pp. 1-12

Vanajakshi, L. \& Rilett, L. R. (2004). A comparison of the performance of artificial neural network and support vector machines for the prediction of traffic speed, IEEE Intell. Vehicles Symp., Parma, Italy, pp. 194-199

Van Lint, J. W. C.; Hoogendoorn, S. P. \& Van Zuylen, H. J. (2002). Freeway travel time prediction with state-space neural networks: modeling state-space dynamics with recurrent neural networks, Proc. 81st TRB Annual Meeting, Washington, D.C.

Van Lint J. W. C.; Hoogendoorn S. P. \& Van Zuylen H. J. (2005). Accurate freeway travel time prediction with state-space neural networks under missing data, Transp. Res., Part C: Emerg. Technol., Vol.13, No.5-6, pp. 47-369

Vlahogianni, E. I.; Golias, J. C. \& Karlaftis, M. G. (2004). Short-term forecasting: Overview of objectives and methods, Transport Rev., Vol.24, No.5, pp. 533-557

Vlahogianni, E. I.; Karlaftis, M. G. \& Golias, J. C. (2005). Optimized and meta-optimized neural networks for short-term traffic flow prediction: A genetic approach, Transp. Res., Part C: Emerg. Technol., Vol.13, No.2, pp. 211-234

Vythoulkas, P. C. (1993). Alternative approaches to short-term traffic forecasting for use in driver information systems, Proc. 12th Int. Symp. Traffic Flow Theory and Transportation, C. F. Daganzo, ed., Berkeley, CA.

Wei, C. H.; \& Lee, Y. (2007). Development of freeway travel time forecasting models by integrating different sources of traffic data, IEEE Trans. on Vehicular Tech., Vol. 56, No. 6, pp. 3682-3694

Wei, L. Y., Fang Z. W., \& Luan, S. (2009). Travel time prediction method for urban expressway link based on artificial neural network. The 5th International Conference on Natural Computation, pp: 358-362

Whittaker, J.; Garside, S. \& Lindveld, K. (1997). Tracking and predicting a network traffic process, Int. J. Forecast., Vol.13, No.1, pp. 51-61

Wild, D. (1997). Short-term forecasting based on a transformation and classification of traffic volume time series, Int. J. Forecast., Vol.13, No.1, pp. 63-72

Williams, B. M. (1999). Modeling and forecasting vehicular traffic flow as a seasonal stochastic time series process, Doctoral dissertation. Department of Civil Engineering, University of Virginia, Charlottesville

Williams, B. M. (2001). Multivariate vehicular traffic flow prediction: an evaluation of ARIMAX modeling, Proc. 80th TRB Annual Meeting, Mira Digital Publishing, Washington D.C.

Williams, B. M.; Durvasula, P. K. \& Brown, D. E. (1998). Urban freeway traffic flow prediction: Application of seasonal autoregressive integrated moving average and exponential smoothing models, Transportation Research Record. 1644, TRB, Washington, D.C., pp. 132-141 
Williams, B. M. \& Hoel, L. A. (2003). Modeling and forecasting vehicular traffic flow as a seasonal ARIMA process: Theoretical basis and empirical results, J. Transp. Eng., Vol.129, No.6, pp. 664-672

Wu, C. H.; Ho, J. M. \& Lee, D. T. (2004). Travel-time prediction with support vector regression, IEEE Trans. Intell. Transp. Syst., Vol.5, No.4, pp. 276-281

Yang, M.L.; Liu, Y.G. \& You, Z.S. (2010). The reliability of travel time forecasting, IEEE Transactions on Intelligent Transportation Systems, Vol.11, No.1, pp. 162-171

Yang, Y. (2004). Combining forecasting procedures: some theoretical results, Econometric Theory., Vol.20, pp. 176-222

Yasdi, R. (1999). Prediction of road traffic using a neural network approach, Neural Comput. Appl., Vol.8, No.2, pp. 135-142

Yin, H.; Wong, S. C.; Xu, J. \& Wong, C. K. (2002). Urban traffic flow prediction using a fuzzy-neural approach, Transp. Res., Part C: Emerg. Technol., Vol.10, No.2, pp. 85-98

You, J. \& Kim, T. J. (2000). Development and evaluation of a hybrid travel time forecasting model, Transp. Res., Part C: Emerg. Technol., Vol.8, No.1-6, pp. 231-256

Yu, L.; Wang, S. \& Lai, K. K. (2005). A novel nonlinear ensemble forecasting model incorporating GLAR and ANN for foreign exchange rates, Comp. $\mathcal{E}$ Oper. Res., Vol.32, No.10, pp. 2523-2541

Yu, L.; Wang, S.; Lai, K. K. \& Nakamori, Y. (2005). Time series forecasting with multiple candidate models: selecting or combining? J. Sys. Sci. \& Complexity., Vol.18, No.1, pp. 1-18

Yun, S. Y.; Namkoong, S.; Rho, J. H.; Shin, S. W. \& Choi, J. U. (1998). A performance evaluation of Neural Network Models in Traffic Volume Forecasting, Math. Comput. Modell., Vol.27, No.9-11, pp. 293-310

Zhang, Y. \& Liu, Y.C. (2008). A Novel Approach to Forecast Weakly Regular Traffic Status, 11th International IEEE Conference on Intelligent Transportation Systems (ITSC 2008), pp: 998-1002, Beijing, China

Zhang, Y. \& Liu, Y.C. (2009a). Data Imputation using Least Squares Support Vector Machines in Urban Arterial Streets, IEEE Signal Processing Letters, Vol. 16, No. 5, pp: 414-417

Zhang, Y. \& Liu, Y.C. (2009b). Missing Traffic Flow Data Prediction using Least Square Support Vector Machines in Urban Arterial Streets, IEEE 2009 Symposium on Computational Intelligence and Data Mining (SSCI2009), Sheraton Music City Hotel, Nashville, TN, USA, 30 Mar. - 2 Apr.

Zhang, Y. \& Liu, Y.C. (2009c). Traffic Forecasting using Least Squares Support Vector Machines, Transportmetrica, Vol. 5, No. 3, pp: 193-213

Zhang, Y. \& Liu, Y.C. (2009d). Traffic Forecasts using Interacting Multiple Model Algorithm, Lecture Notes in Artificial Intelligence (LNAI), Vol. 5579, pp: 360-368

Zhang, Y. \& Liu, Y.C. (2009e). Application of Combined Forecasting Models to Intelligent Transportation Systems, Opportunities and Challenges for Next Generation Applied Intelligence, 22nd International Conference on Industrial, Engineering $\mathcal{E}$ Other Applications of Applied Intelligent Systems (IEA-AIE 2009), Vol. 214, pp: 181-186

Zhang, Y. \& Liu, Y.C. (2009f). Comparison of Parametric and Nonparametric Techniques for Non-peak Traffic Forecasting, Proceedings of World Academy of Science, Engineering and Technology, Vol. 39, International Conference on Computational Statistics and Data Analysis (ICCSDA 2009), pp: 242-248 
Zhang, Y. \& Liu, Y.C. (2010). Analysis of Peak and Non-peak Traffic Forecasts using Combined Models, Journal of Advanced Transportation, Vol. 17, pp: 1-17

Zhang, Y.; Shi, W.H. \& Liu, Y.C. (2010). Comparison of Several Traffic Forecasting Methods based on Travel Time Index Data on Weekends, Journal of Shanghai Jiao Tong University(Science), Vol. 12, No. 2, pp: 188-193

Zhang, C.; Sun, S. \& Yu, G. (2004). A Bayesian network approach to time series forecasting of short-term traffic flows, Proc. 7th IEEE Int. Conf. Intell. Transp. Syst. (ITSC2004), Washington, D.C., pp. 216-221

Zhang, H.; Ritchie, S. G. \& Lo, Z. P. (2000). Macroscopic modeling of freeway traffic using an artificial neural network, Transportation Research Record., 1588, TRB, pp. 110-119

Zhang, X. Y., \& Rice, J. A. (2003). "Short-term travel time prediction." Transp. Res., Part C: Emerg. Technol., 11(3-4), 187-210

Zheng, W. Z.; Lee, D. H. \& Shi, Q. X. (2006). Short-term freeway traffic flow prediction: Bayesian combined neural network approach, J. Transp. Eng., Vol. 132, No.2, pp. 114-121

Zhong, M.; Sharma, S. C. \& Lingras, P.(2004). Genetically designed models for accurate imputations of missing traffic counts, Transp. Res. Rec. 1879, J. Transp. Res. Board, TRB, Washington, D. C., pp. 71-79 


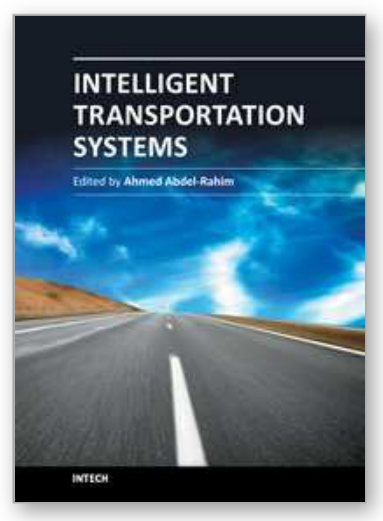

\author{
Intelligent Transportation Systems \\ Edited by Dr. Ahmed Abdel-Rahim
}

ISBN 978-953-51-0347-9

Hard cover, 206 pages

Publisher InTech

Published online 16, March, 2012

Published in print edition March, 2012

Intelligent Transportation Systems (ITS) have transformed surface transportation networks through the integration of advanced communications and computing technologies into the transportation infrastructure. ITS technologies have improved the safety and mobility of the transportation network through advanced applications such as electronic toll collection, in-vehicle navigation systems, collision avoidance systems, and advanced traffic management systems, and advanced traveler information systems. In this book that focuses on different ITS technologies and applications, authors from several countries have contributed chapters covering different ITS technologies, applications, and management practices with the expectation that the open exchange of scientific results and ideas presented in this book will lead to improved understanding of ITS technologies and their applications.

\title{
How to reference
}

In order to correctly reference this scholarly work, feel free to copy and paste the following:

Yang Zhang (2012). How to Provide Accurate and Robust Traffic Forecasts Practically?, Intelligent Transportation Systems, Dr. Ahmed Abdel-Rahim (Ed.), ISBN: 978-953-51-0347-9, InTech, Available from: http://www.intechopen.com/books/intelligent-transportation-systems/how-to-provide-accurate-and-robusttraffic-forecasts-practically-

\section{INTECH}

open science | open minds

\author{
InTech Europe \\ University Campus STeP Ri \\ Slavka Krautzeka 83/A \\ 51000 Rijeka, Croatia \\ Phone: +385 (51) 770447 \\ Fax: +385 (51) 686166 \\ www.intechopen.com
}

\author{
InTech China \\ Unit 405, Office Block, Hotel Equatorial Shanghai \\ No.65, Yan An Road (West), Shanghai, 200040, China \\ 中国上海市延安西路65号上海国际贵都大饭店办公楼 405 单元 \\ Phone: +86-21-62489820 \\ Fax: +86-21-62489821
}


(C) 2012 The Author(s). Licensee IntechOpen. This is an open access article distributed under the terms of the Creative Commons Attribution 3.0 License, which permits unrestricted use, distribution, and reproduction in any medium, provided the original work is properly cited. 